and during the summer, lectures and demonstrations are given on the plots. In Norfolk there are no definite fixed stations, but the use of land has been granted by farmers for experiments on the effect of manures on crops grown in the ordinary course of farming. Feeding experiments have also been conducted.

A paper from Prof. H. W. Vogel was read, in his absence, by the Secretary, dealing with the history of the development of orthochromatic photography. Photographs were shown illustrating the advantages of the use of eosin-silver as a sensitiser, the plates being more sensitive to the yellow rays than plates prepared with ordinary eosin.

Mr. C. H. Bothamley read a paper, illustrated by lantern slides and specimens, on the sensitising action of dyes on gelatino-bromide plates. The manner in which the dye acts was discussed, experimental evidence being given against Abney's view that an oxidation product, formed by the action of light on the dye, is the active agent in assisting the reduction of the silver bromide by the developer. The probabilities appear more in favour of Eder's view that the dye or sensitiser absorbs the energy of the light waves, and passes that energy on to the silver bromide with which it is associated, the silver bromide being thereby decomposed, and the so-called latent image being formed.

In reply to questions by Lord Rayleigh, Dr. Kohn, and Dr. Harden, Mr. Bothamley said that, so far as he was aware, photo-chemical action is always preceded by the absorption of light-waves, and in the case of colourless substances it is the ultra-violet rays that are absorbed and do the chemical work. Although the quantitative composition of the latent image is not known, we have, as a matter of fact, considerable knowledge as to its properties. There is no difficulty in determining the absorbing action and the sensitising effect on two contiguous strips of the same plate, and therefore under strictly comparable conditions. No relation can be traced between the fluorescence of a dye and its sensitising action.

The report of the Committee for investigating the action of light upon dyed colours was read by the President. With some few exceptions, all the available red, orange, and yellow colours, as applied to wool and silk, have now been exposed. (Tables are appended giving the general result of the exposure.) As before, it is found that many natural dye-stuffs are by no means so fast as is generally supposed, and are exceeded in this respect by artificial colouring matters.

Two papers on organic chemistry were contributed by Dr. I. J. Sudborough. In the first paper, the anthor describes the preparation of a monochloro-stilbene from deoxy-benzoin, differing from that described by Linin, as it is a solid, crystallising from alcohol in large colourless plates. An oily compound, corresponding to that of Linin, has been prepared, and is being further investigated. Other stilbene derivatives are described.

In a note on the constitution of camphoric acid, the author draws attention to the fact that, as regards its etherification, camphoric acid shows a marked resemblance to some of the polycarboxylic acids investigated by Victor Meyer and Sudborough and to hemi-mellitic acid. The formula of Armstrong and of Bredt are regarded as best agreeing with the behaviour of camphoric acid in this respect.

Mr. H. J. H. Fenton gave an account of the preparation and properties of a new organic acid obtained by oxidising tartaric acid under certain conditions in presence of a ferrous salt. It can be obtained by the oxidation of moist ferrous tartrate in the air, and it is found that this reaction is much accelerated by light. The acid has been isolated, and proves to be a dibasic acid having the formula $\mathrm{C}_{4} \mathrm{H}_{4} \mathrm{O}_{6}+2 \mathrm{H}_{2} \mathrm{O}$. It gives a beautiful violet colour with ferric salts in presence of alkali. The constitution of the acid is under investigation. Heated with water it is resolved into carbon dioxide and glycollic aldehyde, the latter substance polymerising to form a sweet-tasting solid gum having the formula $\mathrm{C}_{6} \mathrm{H}_{12} \mathrm{O}_{6}$.

The Committee for investigating isomeric naphthalene derivatives report that the fourteen isomeric tri-chlor derivatives have been obtained.

Dr. M. Wildermann read two papers on physical chemistry. In the first, experimental evidence was quoted, showing the validity of Van 't Hoff's constant, Dalton's law, \&c., for very dilute solutions. In the second paper, on the velocity of reaction before perfect equilibrium takes place, an attempt was made to develop equations of equilibrium from experiments made by others on the rate of solidification of phosphorus and other substances.

$$
\text { NO. } 1352 \text {, VOL. } 52 \text { ] }
$$

Messrs. C. F. Cross and C. Smith contributed a paper on the chemical history of the barley plant. The work had been carried out during the two years 1894 and 1895 on the experimental plots at Woburn, and the general conclusions drawn were that the conditions of soil nutrition had very little influence upon the composition of the plant; that the straw grown in wet seasons had a high feeding value and conversely a low paper-making value; and that the compounds known as furfuroids were continuously assimilated to permanent tissue in a normal season, but in a very dry season the permanent tissue is drawn upon by the growing plant for nutrient material which is ordinarily drawn from the cell contents.

\section{THE RETIREMENT OF PROFESSORS.}

TIE report of the Committee appointed by the Treasury to consider the question of the desirability of a fixed age for the compulsory retirement of professors serving under the Crown has been recently published as a Parliamentary paper. The Com mittee consisted of Lord Playfair, Lord Welby, and Sir M. W. Ridley, M.P. Mr. C. L. Davies was secretary. The report, which is addressed to the Lords Commissioners of her Majesty's Treasury, is in the following terms :-

We have taken the evidence of presidents and professors of the Queen's Colleges in relation to their retirement upon superannuation at fixed ages, as determined by the Order in Council of August I5, I 890 . We are of opinion that the Commission of I888, upon the report of which, to some extent, that Order in Council was based, did not intend that the limitations of age applied to Civil servants generally should be deemed applicable to presidents and professors of colleges, who are appointed and serve under different conditions from those which prevail in the Civil Service.

These presidents and professors are appointed at a maturer age, and have, by the nature of their employment at seats of learning, less tendency than Civil servants to become inefficient at the age of sixty-five. Indeed, up to that age it is often found that their efficiency increases, by experience in teaching, as their age progresses, though undoubtedly a time does arrive when advanc. ing age weakens the receptivity of the professor to new dis. coveries in science, and diminishes the inclination to alter his instruction in order to adapt it to these changes. When this occurs the students are the sufferers. In the German Univer. sities this well-known degeneration of intellectual activity among the aged is partly compensated by the appointment of active young " extraordinary professors," who, though not on the ordinary staff of the colleges, are allowed to give competing lectures within their walls. In Edinburgh an extra-mural competition is encouraged, and in each Scotch University, when professors show diminished efficiency through age, it is the duty of the University court to superannuate the professor under a pension scheme, which is charged upon a fixed Parliamentary vote for all the Scotch Universities. The Queen's Colleges in Ireland are in a different position, for they are only to a small extent dependent upon votes in Parliament, being mainly supported out of the Consolidated Fund. They are, in consequence of this peculiarity, in more intimate connection with the executive Government, with which the presidents are in frequent communication as to the working of the college and the efficiency of the professors, who are appointed by the Crown and can be dismissed by the Crown. The statutes which govern the Colleges also emanate from the Crown, and are not, like those of other colleges, the product of academic autonomy.

Under these circumstances, we are of opinion that there should be fixed rules as to superannuation of presidents and professors, and that they should be made by college statutes and not by an Order in Council.

We are of opinion that when a professor reaches sixty-five years of age the president of the college should be bound to report to the Government the condition and efficiency of the teaching. If these are and continue to be satisfactory, the professor need not be superannuated till seventy, but at this age his retirement should be absolute.

In regard to presidents, we are of opinion that the age of seventy should be the period of retirement, but, should the visitors of the college formally report that the college would suffer by the loss of the experience which the president has acquired, we think that the Treasury, and not the Irish Office, should have power to continue him as president for a certain 
number of years not exceeding five, so that at the age of seventyfive the retirement of a professor should be absolute.

We are quite aware that there are cases where professors at seventy and presidents at seventy-five are fully competent to discharge their duties, but the advantages derived from superannuation would be seriously diminished if, to meet these rare cases, there were uncertainty in regard to the application of a general rule. We have observed with regret that the alumni of the Queen's Colleges do not seek to go back to them as professors, and it was explained to us that one reason for this is that it is useless for them to prepare for a professorial career in these colleges while so much uncertainty prevails as to when the chairs will become vacant.

We also took the evidence of Profs. Lockyer and Rücker as to the conditions which prevail in the Government School of Science at South Kensington, and we found that the age of seventy for professors was considered a proper age for retirement under ordinary circumstances.

In our opinion, as the professors are not appointed till middle life, the addition of seven years to their period of service in calculating the amount of their superannuation obviously tends to secure eminent specialists as candidates for office. The power of voluntary retirement at the age of sixty has also much to commend it in this sense.

We have the honour to be Your Lordships' obedient servants, Playifir. WelBy.

August 5, I895. M. W. Ridley.

The report is followed by the minutes of evidence taken on June 17,18 , and 19 , during which nine witnesses were examined.

\section{UNIVERSITY AND EDUCATIONAL INTELLIGENCE.}

We learn from Science, that Prof. Strahl, of Marburg, has been called to the chair of Anatomy in the University of Giessen, Prof. Hans Lenk, of Leipzig, to that of Geology in the University of Erlangen, and that Dr. Haecker, of Freiburg i. B., and Dr. v. Dalla-Torre, of the University of Innsbruck, have been made assistant Professors of Zoology.

PROF. ChapMAN having resigned the professorship of Geology and Mineralogy in the University of Toronto, that chair is now vacant.

AcCording to Science, the conditions attached to the bequest made by the late Sir William Macleay to the Sydney University, to found a chair of Bacteriology, are such that the University has decided to decline the bequest. The money will therefore revert to the Linnean Society of New South Wales, to maintain a bacteriologist, who will carry on bacteriological investigations and also take pupils.

The Examinations for the Royal Agricultural Society's Junior Scholarships have been fixed to take place on November i 2 and I3 next, at the schools of candidates and at the Society's house, I3 Hanover Square. Ten scholarships of $f 20$ each are thrown open for competition by candidates between the ages of fourteen and eighteen, and the subjects of examination comprise: (I) The Principles of Agriculture, especially with reference to the rotation of crops, the nutrition of plants and animals, and the mechanical cultivation of the soil ; (2) Chemistry as applied to Agriculture; (3) Elementary Mechanics as applied to Agriculture ; (4) Land Surveying. The latest date for receiving entries is October 15 .

THE following courses of Gresham Science lectures are announced :- " Physic," by Dr. Symes Thompson, on October 8 to II ; "Astronomy," by Rev. E. Ledger, on October 22 to 25 ; "Geometry," by Mr. W. H. Wagstaff, on November I9 to 22. The lectures will all be delivered at six o'clock in the theatre of Gresham College, E.C.

THE London Society for the Extension of University Teaching announces that, in co-operation with the Royal Geographical Society, arrangements have been made for the delivery at Gresham College of a course of twenty-five lectures by Mr. H. J. Mackinder, on "The Principles of Geography." The course is specially arranged for pupil teachers, and the Sessional Certificate, granted in connection therewith, will carry marks at the Queen's Scholarship Examination. The lectures will be given on Monday evenings at six o'clock, beginning October 7 .

AT the City of London College, Moorfields, a course of twenty-five lectures on "The History of Chemical Discovery" will be delivered, under the auspices of the London Society for the Extension of University Teaching, by Prof. W. Ramsay, F.R.S. The course will be begun on Tuesday evening, October 8, at eight o'clock, and be continued weekly.

ON Tuesday evening, October I, Sir Henry E. Roscoe will presicie at a meeting at the Royal Victoria Hall, Waterloo Bridge Road, when the presentation of certificates to students of the Morley Memorial College will take place. The lecture arrangements at the Royal Victoria Hall for the month of October are as follow:-On the 8th, Mr. W. P. Bloxam will lecture on "Combustion"; on the I5th, Dr. W. D. Halliburton will lecture on the "Human Brain"; and on the 22nd, Mr. P. J. Hartog will lecture on "Lavoisier."

\section{SCIENTIFIC SERIALS.}

American Tournal of Sicnce, September.-Distribution and secular variation of terrestrial magnetism, by L. A. Bauer. Starting from the supposition that the earth is magnetised symmetrically to its axis of rotation, the author shows that the chief canse of distortion of this primary fiekl can be represented as due to a secondary polarisation approximately equatorial in direction. Of these two systems, the polar systems would have to be five or six times stronger than the equatorial. Since, in going round the earth along a geographical parallel of latitude, the deflections due to the secondary system almost balance each other, the inference might be drawn that the secondary field is in some way connected with the earth's rotation.--Relations of the diurnal rise and fall of the wind in the United States, by Frank Waldo. For January the rise of wind towards the mid-day maximum is followed by a more rapid fall over nearly the whole of the United States. For July the same law holds, except in the Western States, where the morning rise is more rapid. As regards the time during which the wind rises, this is about seven hours in the Mississippi valley. On the Atlantic coast there is a decrease from ten hours in the north to five hours on the coast of Florida. - The rate of increase varies from 0.4 to 0.6 miles per hour. Native sulphur in Michigan, by W. H. Sherzer. During the past year interesting deposits of sulphur have been discovered in the Upper Helderberg limestone, of Monroe County, Michigan. The sulphur bed lies from sixteen to eighteen feet below the surface between a compact, dolomitic limestone and a calcareous sand rock. The sulphur generally occurs in bright lustrous masses towards the centre of the cavity, intermatted frequently with the above minerals. Fragments as large as a fist are readily removed. Some of the smaller cavities contain nothing but sulphur, and one was found filled with selenite crystals. About an acre of this bed had been removed when the locality was visited, and from this the superintendent estimated that one hundred barrels of pure sulphur had been obtained.

Wiedemann's Annalen der Physik und Chemie, No. 8.Simple objective presentation of the Hertzian reflection experiments, by Victor Biernacki. The author places one of Lodge's "coherers" in the focal line of the secondary mirror. Under these conditions, mirrors with a length as small as $45 \mathrm{~cm}$. and an aperture of $30 \mathrm{~cm}$., with a focal length of $3 \mathrm{~cm}$., exhibit the reflection phenomena well. The coherer employed is a horizontal glass tube filled with copper filings, whose resistance is reduced as soon as electric oscillations impinge upon it. The polarisation experiment is easily performed with a tiled wall, which behaves as a transparent solid to the electric rays. A striking experiment analogous to the introduction of a doublyrefracting crystal between two crossed nicolls is the introduction of a thick slab of good ice between the two crossed mirrors, with its axis of $45^{\circ}$ to both the focal lines. The galvanometer connected with the coherer, which before was motionless, now gives a distinct reflection, thus showing the doubly-refracting nature of ice.-A convenient method for showing the electric refractive powers of liquids, by P. Drude. For this purpose, strong oscillations are necessary. These may be produced by a modification of Blondlot's arrangement, using an exciter without a condenser, whose total length is slightly smaller than half the wave-length required. The wave-lengths in water and other

NO. I 352 , VOL. 52 ] 